\title{
الرد على المخالف الأهمية والضوابط
}

محمد بن غالب حسان 1

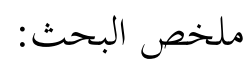

تقوم دراسة البحث حول مسألة الرد على المخالف، والذي يتضمن ذكر أنواع المخالفات وضوابط الرد على المخالف، إذ هذه المسألة وقع الناس فيها بين إفراط وتفريط فكان لابد من بيان أهميتها، وضبط مسائلها. وتتجلى أهداف البحث في أمور عدة منها : الحرص على امتثال الأمر الإلهي في الأمر بالاجتماع وكذلك أن يعرف الإنسان أسباب سلوك الباطل؛ لئلا يشتبه عليه بالحق، وتبصير المسلمين بمعرفة أهمية هذا الباب، والذي هو صمام أمان للأمة أمام جراءة المنحرفين، وتعدي الضالين، وزيغ المبطلين. وقد استعمل الباحث المنهج الاستنباطي للنصوص وكلام العلماء في المسألة، وذيل البحث بخاتمة ذكر فيها أهم النتائج والتي من أهمها: أن الخلاف أمر كوني واقع في هذه الأمة، وأن الخلاف ينقسم إلى خلاف سائغ وخلاف غير سائغ، وكذلك بيان أن لكل نوع من نوعي الخلاف أسباب ومظاهره، وأن الرد على المخالف له الأهمية البالغة في شريعة الإسلام.

Abstract

The research study revolves around the issue of refuting the opposer. It includes the mention of the types of oppositions and the principles of refuting the opposer as people have fallen either into excessiveness or negligence regarding this issue, and so it was necessary that its importance be clarified and its matters regulated.The objectives of the research are evident in several matters, which include Striving to obey the divine command of Allah regarding unity, as well as for a person to know the reasons that lead to following falsehood, lest it be confused with truth, and enlightening the Muslims with knowing the importance of

$$
1
$$


27

محمد بن غالب حسان

this chapter, which is a safety valve for the Ummah (Islamic nation) against the audacity of the deviants, the transgression of the astray, and the deviation of the invalidators. The researcher has used the qualitative approach towards the texts and the words of scholars on the issue and has followed the research with a conclusion in which he mentioned the most important results, of which the most important are: that disagreement is a kaouni (what Allah has decreed for a reason but not loved) matter in this nation, that disagreement is of two types: a valid disagreement and an invalid disagreement, as well as the clarification that each type of disagreement has its reasons and its manifestations, and that the refutation of the opposer has an utmost importance in the Sharia of Islam (Islamic legislation).

الحمد لله، نحمده تعالى ونستعينه ونستغفره، ونعوذ بالله من شرور أنفسنا ومن سيئات أعمالنا, من يهده الله فلا مضل له، ومن يضلل فلا هادي له، وأشهد أن لا إله إلا الله وحده لا شريك له.

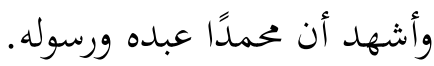

أما بعد: فإن النصوص الشرعية جاءت بالدعوة إلى الائتلاف والاجتماع وترك التفرق والاختلاف، وهذا أمر لا يرتاب فيه عاقل، ومع صدق هذه الحقيقة وظهورها وجلائها، إلا أن الأمة مختلفة اختلافا ظاهرا، وقد سلك فئام من الناس أسباب الاختلاف والافتراق سواء كان هذا بتأويل أو هوى، ولأهمية الموضوع، ووقوع مسألة الرد على المخالف بين إفراط وتفريط، وبين غلو وجفاء، فمن الناس من ينكرها البتة مدعيا بذلك الحرص على اجتماع الأمة، وبين مفرّط في ذلك سالكا في ردّه مسلكا مشينا بعيدا عن الضوابط الشرعية والقواعد المرعية، وعنونت لهذه الدراسة ب:" الرد على المخالف، الأهمية والضوابط"

$$
\text { الأهمية: تتجلى أهمية الدراسة فيما يلي: }
$$

أولا: الحرص على امتثال الأمر الإلهي في الأمر بالاجتماع في آيات كثيرة منها قوله تعالى

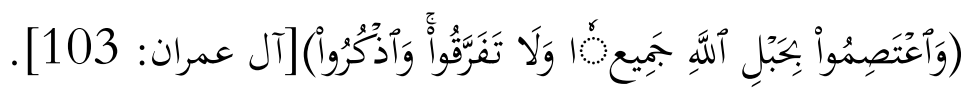


ثانيا: أن يعرف الإنسان أسباب سلوك الباطل؛ لئلا يشتبه عليه بالحق. وهذا أمر حرص عليه الصحابة -رضي الله عنهم وأرضاهم-؛ ففي حديث حذيفة -رضي الله عنه- قال: لاكان الناس يسألون رسول الله -صلى الله عليه وسلم- عن الخير، وكنت أسأله عن الشر؛ خخافة أن يدركني《. ثالثا: تبصير المسلمين بمعرفة أهمية هذا الباب، والذي هو صمام أمان للأمة أمام جراءة المنحرفين، وتعدي الضالين، وزيغ المبطلين مشكلة البحث: تتجلى مشكلة البحث في وجود انفلات ظاهر في مسألة الرد على المخالف، بين من يمنع الردود بدعوى الاجتماع وتوحيد الكلمة، وبين من يفتح بابا للردود دون ضوابط أو

$$
\text { تقييدات مرعية في ذلك. }
$$

وقفت على دراستين في هذا المجال:

الأولى: فقه الرد على المخالف، د. خالد السبت، وهو بحث موسع في هذا الباب، ركز فيه الباحث على منهج الرد على المخالف، ويفترق ذلك بأن دراستي هذه عن الآثار والضوابط. الثانية: أهميَّة الرَِّّ على المخالفِ وبيانُ جملةٍ من ثمارِه، الدكتور عبد الله البخاري. وهو بحث في بيان أهمية هذا الباب، وبيان ثماره.

$$
\text { منهجية البحث: كان منهجي في البحث على النحو التالي: }
$$

2- أمّا طريقة العزو في البحث، ففي نصوص الكتاب العزيز أعزو إلى السورة ثم الآية، ويكون ذلك في المتن. وفي نصوص الحديث والآثار أعزو إلى الكتاب ثم الجزء والصفحة ثم رقم

$$
\text { الحديث أو الأثر إن وجد في الحاشية. }
$$

3- استعملت المنهج الاستباطي، بحيث انطلقت من دلالات النصوص على المقاصد المطلوبة 
29

4- حرصت على اختيار الأسلوب الأمثل في الألفاظ ما أمكن، واستعنت على ذلك بعلامات

$$
\text { الترقيم المعروفة. }
$$

5- - جعلت فهرسا للمصادر والمراجع التي تم الإحالة إليها

هذا وأسأل الله الكريم رب العرش العظيم أن أكون قد وُفقت في هذا البحث المختصر، وأن يجعله خالصاً له سبحانه، وهذا جهد المقلّ، فما كان فيه من صواب فمن الله وحده، وما كان فيه من زلل فمني ومن الشيطان، وصلى الله على نبينا محمد وعلى آله وصحبه وسلم تسليماً كثيراً.

تمهيد: إنّ الخلاف حاصل في هذه الأُمَّة، وهو أمر قد أخبر عنه الله -جل وعلا-، وأخبر عنه النبي

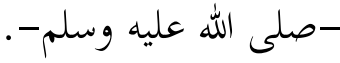

ويدل على ذلك حديث العرباض بن سارية المشهور: >(فعليكم بسنتي، وسنة الخلفاء الراشدين المهديين من بعدي، تمسَّكوا بها، وعَضّوا عليها بالنواجذه،. وأول هذا الحميث قوله -عليه الصلاة والسلام-: إفإنه من يعش فيكم فسيرى اختلافًا كثيرال ) (Attirmidhi,no:2676; Alqizwaani,no:43)، ثم أرشد الرسول -عليه الصلاة والسلام- إلى السبيل القويم للنجاة من هذا الاختلاف، وهو الرجوع إلى سنته -عليه الصلاة والسلام-. والمراد به في هذا الحديث إلى دينه؛ لأن السَّنَّة تطلق ويراد بها الدين كله. فأمر الاختلاف أمر حاصل، وهي سنة قدرية أرادها الله -جل وعلا- قدرًا وكونًا في هذه الأُمَّة، وإن أراد الله من الأمة شرعا الاجتماع وترك الافتراق والتنازع كما سبق. 


\section{المبحث الأول : مفهوم الرد على المخالف وأنواع الحلاف : وفيه مطلبان : المطلب الأول : التعريف بالحلاف في اللغة والاصطلاح :} المسألة الأولى : الخلاف لغة: الخلاف والاختلاف والمخالفة في اللغة بمعنً واحد, وأصل مادتا قال ابن فارس -رحمه الله-: "الخاء واللام والفاء, أصولٌ ثلاثةُ: أحدُها: أن يجيءُ شيءٌ بعدَ شيءٍ يقومُ مقامَه، والثاني: خِلافُ قُدََّم، والثالث: التغيُّر (Alraazi, 1399h)". والمخالف اسم المفعول من مادة " خالف ", يخالفُ خِلافاً ومُخالفةً (Ibn Manzur). المسألة الثانية: الاختلاف اصطلاحا: لا يختلف المعنى الاصطلاحي للخلاف عن المعنى اللغوي ، إلا أنه الكلام عنه في جانب المسائل الشرعية ، فالعلاقة بين المعنيين هي علاقة عموم وخصوص مطلق ، ذلك أن علماء الشريعة يطلقون الخلاف على المسائل الشرعية التي لم يجمع عليها ، فالخلاف ضد الإجماع .

ويمكن صياغة تعريف شرعي للاختلاف بأنه: "تعارض الآراء في مسألة شرعية، لا نص فيها ولا إجماع، بحيث لا يمكن الجمع بين الأقوال المختلفة".

المطلب الثاني : أنواع الخلاف: يككن أن نذكر بشكل عام أن الخلاف ينقسم إلى قسمين رئيسين، وهما الخلاف السائغ

$$
\text { وألخلاف غير السائغ، وفي كل من هذين القسمين تفريعات سيأي ذكرها: }
$$

من تأمل في كلام العلماء سواء في كلامهم عن المسائل الفرعية أو غيرها مما هو مجال للخلاف

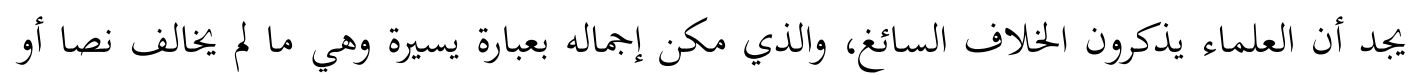
إجماعا، فإن مخالفة النص أمر لا يسوغ إذ التعبد لله تعلى هو بتحكيم النص سواء في مسائل 
31

الاعتقاد أو الفقه أو غيرها، والإجماع كذلك لا تجوز مخالفته وهو الإجماع المتحقق الصحيح لقوله صلى الله عليه وسلم: " إن الله قد أجار أمتي من أن تجتمع على ضلالة (Alshaybany)". وأوجه هذا النوع من الخلاف متعددة، ويمكن حصر أسباها فيما يأتي (Ibn Uthaymin): السبب الأول: أن يكون الدليل لم يبلغ هذا المخالف الذي أخطأ في حكمه. وهذا السبب ليس خاصَّا فيمن بعد الصحابة، بل يكون في الصحابة ومَن بعدهم. السبب الثاني: أن يكون الحديث قد بلغ الرجل ولكنه لم يثق بناقله ورأى أنه مخالف لما هو أقوى

$$
\text { السبب الثالث: أن يكون الحديث قد بلغه ولكنه نسيه }
$$

السبب الخامس: أن يكون قد بلغه الحديث لكنه منسوخ ولم يعلم بالناسخ السبب السادس: أن يعتقد أنه معارض بما هو أقوى منه من نص أو إجماع السبب السابع: أن يأخذ العالم بحديث ضعيف أو يستدل استدلالاً ضعيفاً.

\section{ثانيا: الحخلاف غير السائغ:}

$$
\begin{array}{r}
\text { ويمكن حصر هذا الخلاف بشكل عام في الجوانب التالية: } \\
\text { الجانب الأول: الاختلاف في أصول الاعتقاد: }
\end{array}
$$

فأصول العقيدة أمور متفق عليها، لا يجبوز بحال من الأحوال الاختلاف فيها، وأما وقوع بعض الخلاف في أبواب من العقيدة فإنما هو في فرعياتا لا أصولما، ويعود الخلاف فيها إلى خلاف الأفهام لا إلى مصادمة النصوص وردها، وفي ذلك يقول ابن عثيمين رحمه الله: " لا يمكن أن نقول: إن جميع مسائل العقيدة يجب فيها اليقين؛ لأن من مسائل العقيدة ما اختلف فيه العلماء رحمهم الله، وما كان مختلفا فيه بين أهل العلم فليس يقينيا؛ لأن اليقين لا يمكن نفيه أبدا... والقول بأن العقيدة ليس فيها خلاف على الإطلاق غير صحيح، فإنه يوجد من مسائل العقيدة ما يعمل فيه الإنسان بالظن ( Al 


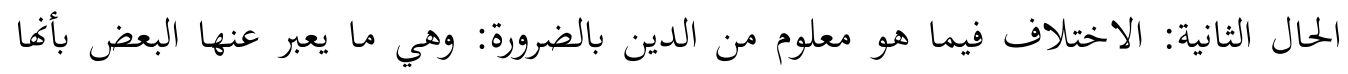
قطعية الثبوت وقطعية الدلالة، مثل وجوب الصلاة والصيام والزكاة، والحج، وتحريم الفواحش كالزنا

$$
\text { واللواط والربا ونحو ذلك }
$$

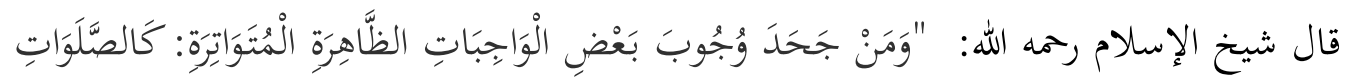

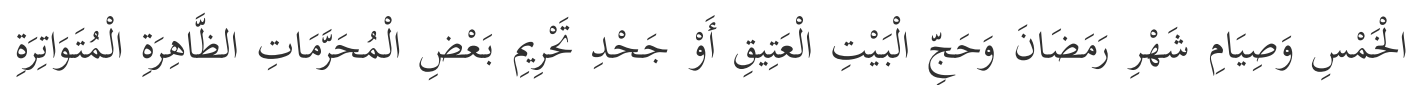

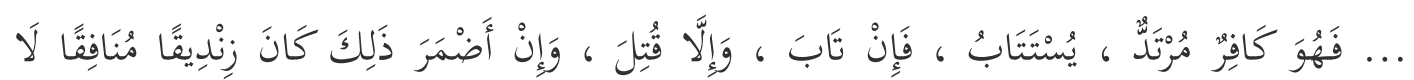

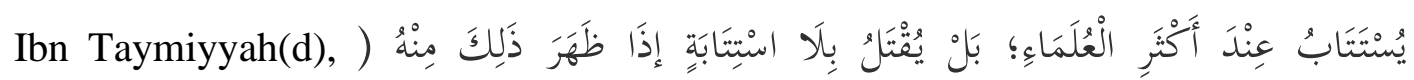
."1416h

$$
\text { الحال الثالثة: الاختلاف بمجرد الموى لا بدليل وحجة: }
$$

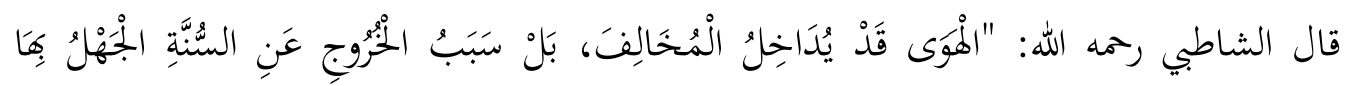

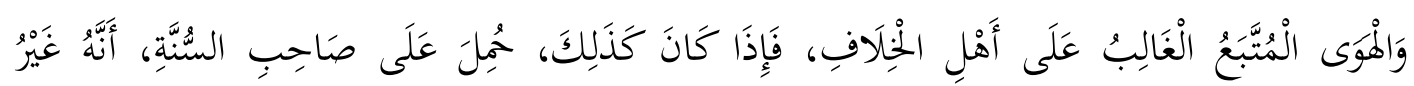

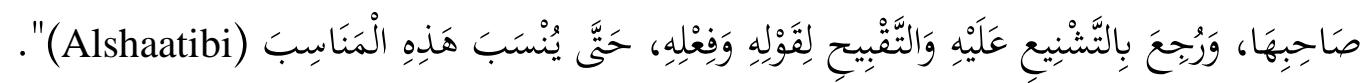

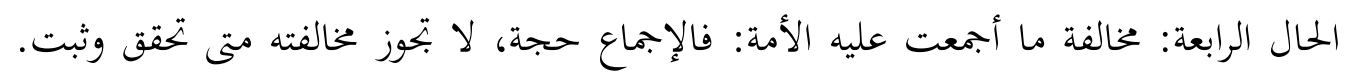

$$
\text { لقوله صلى الله عليه وسلم " لا تجتمع أمتي على ضلالة". }
$$

ولذلك روي عن الإمام أحمد أنه قال : "من خَالف الِِْمَّاع والتواتر فَهُوَ ضال مضل ( Abu

."(Bakr Al’khilal

\section{المبحث الثاني: أهمية الرد على المخالف :}

قبل البدء ببيان أهمية الرد على المخالف، يجسن ذكر مشروعية الرد على المخالف من الكتاب

والسنة، ووصايا العلماء في ذلك: وهو ما سينضوي بإذن الله في المطلب الآي:

المطلب الأول : أدلة مشروعية الرد على المخالف : 
33

محمد بن غالب حسان

لقد ثبتت مشروعية مبدأ الرد على المخالف من كتاب الله تعالى, وسنة النبي صلى الله عليه وسلم وعمل سلف الأمة, "فالكتب المنزلة من السماء والأثارة من العلم المأثورة عن خاتم الأنبياء يميز

الله بها الحق من الباطل, ويحكم بين الناس فيما اختلفوا فيه (Ibn Taymiyyah(d), 1416h)". أولاً : من القرآن الكريم : قوله تعالى رادا على أقوال باطلة مناقضة لتوحيده ركََذْ كَفَرَ اللَّذِينَ

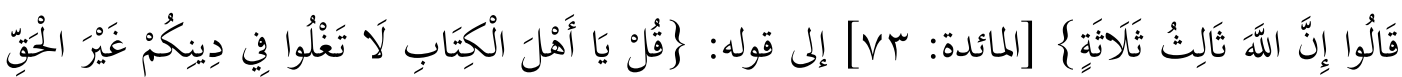

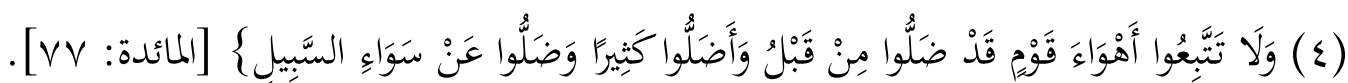
قال شيخ الإسلام رحمه الله :"وهذا خطاب للنصارى كما دل عليه السياق، ولذذا غاهم عن الغلو، وهو مجاوزة الحد، كما هاهم عنه في قوله: $\}$ يَا أَهْلَ الْكِتَابِ لَا تَغْلُوا فِي دِينِكُمْ

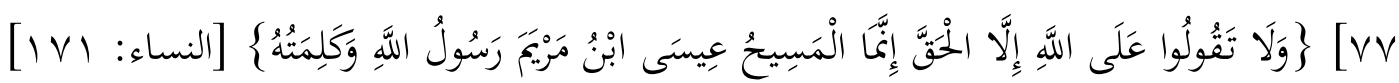

(Ibn Taymiyyah $(\mathrm{a})) \ll$

ثانياً: من أدلة السنة النبوية : إن السنة النبوية حافلة بالأدلة التي تدل على مشروعية الرد على المخالفين؛ من قوله وفعله وتقريره . فمن أقواله صلى الله عليه وسلم الدالة على مشروعية ذلك ما ورد عن عدد من الصحابة ب أنه صلى الله عليه وسلم قال: ( يحمل هذا العلم من كل خلف عدوله, ينفون عنه تحريف الغالين, وانتحال المبطلين, و تأويل الجاهلين ) (Abu Ja'far). ومن أفعاله صلى الله عليه وسلم المبينة لتلك المشروعية رده صلى الله عليه وسلم على عثمان بن مظعون $\tau$ تبتله (Al-Bukhari, no:5073; Muslim, no:1402).

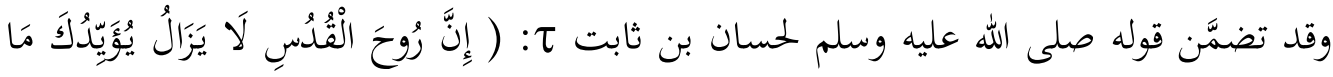
نَفَحْتَ عَنْ اللَّهِ وَرَسُوِلهِ ), وقالت عائشة رضي اله عنها: ( سَمَعْتُ رَسُولَ اللَّهِ صلى الله عليه وسلم يَقُولُ: هَجَاهُمْ حَسَّانُ فَشَفَى وَاشْتَفَىى) (Muslim, no:2490), السنة القولية والفعلية والتقريرية عن صلى الله عليه وسلم في الرد على المخالفين من الكفار. 
ثالثاً: من أقوال العلماء في أهمية الرد على المخالف : عبارات أهل العلم كثيرة في هذا الجانب، وحسبنا هنا أن نذكر شيئا يسيرا من كلامهم وتقريراتم والتي تتضح به معالم منهجهم، فمن هذه

قالَ الإمامُ عثمان بن سعيد الدارمي :" فحينَ رأينا ذلكَّ منهم، وفطنَّا لمذهبهم، وما يَقصدونَ إليه من الكُفر وإبطالِ الكتُب والرُّل، ونفي الكَلام والعِلْم والأمر عن الله تعالى، رأينا أنْ نُبِّنْ من

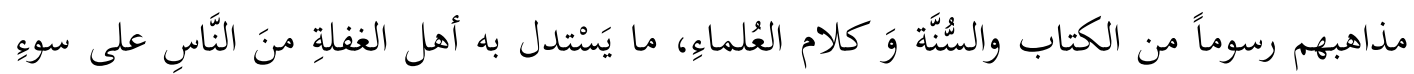
مذْهَبهم، فيحذروهم على أنفسهم وعلى أولادهم وأهليهم، ويِتتهدونَ في الرَّدِ عليهم، محتسبين منافحين عن دين الله تعالى، طالبين به ما عند الله (Ahmad Bin Hanbal(a)". وقال ابن القيم -رحمه الله- مشيراً إلى حرص السلف على الرد على المخالفين: ( فكل بدعة مضلة في الدين أساسها القول على الله بلا علم ، ولهذا اشتد نكير السلف والأئمة لها, وصاحوا بأهلها من أقطار الأرض, وحذروا فتنتهم أشد التحذير, وبالغوا في ذلك ما لم يبالغوا مثله في إنكار الفواحش والظلم والعدوان؛ إذ مضرة البدع وهدمها للدين ومنافاتها له أشد) (b) (Ibn Alqayyim(). فبذلك تبين لنا أهمية مبدأ الرد على المخالف للحق والصواب من خلال ما ذكرنا من من نصوص الكتاب والسنة, وحرص سلف الأمة على تطبيقه.

\section{المطلب الثاني: مقاصد الرد على المخالف:}

يدرك كل عاقل أن الرد على المخالف ليس مقصودا لذاته، وإنما المراد بذلك رفعة الحق والذب عن الدين وحماية معالمه وتشريعاته، وهذا ما سأبينه في المقاصد التالية:

\section{المقصد الأول: رفعة الحق والدفاع عنه :}

قال النسفي -رحمه الله-: (( هو الذي أرسل رسوله محمدا عليه السلام (بالهدى ) بالقرآن ودين الحق الإسلام (ليظهره) ليعليه (على الدين كله) على أهل الأديان كلهم, أو ليظهر دين الحق على كل دين)( Abu Albarakat) 
35

$$
\text { محمد بن غالب حسان }
$$

ولذلك كان أهل الإسلام من علماء الدين وفقهائه من أحرص الناس على رفعة الدين، دون

$$
\text { مبالاة بمعترض أو متعض لا يقبل الحق أو لا يرفع رأسا به. }
$$

قال ابن رجب رحمه الله:" فلو فرض أن أحداً يكره إظهار خطئه المخالف للحق فلا عبل عبرة

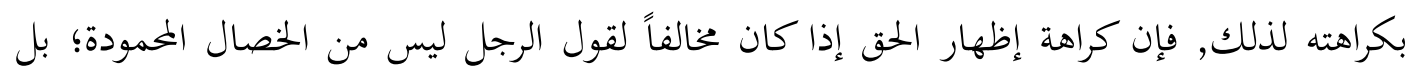
الواجب على المسلم أن يحب ظهور الحق ومعرفة المسلمين له سواءٌ؛ كان ذلك في موافقته أو مخالفته

."(Ibn Rajab)

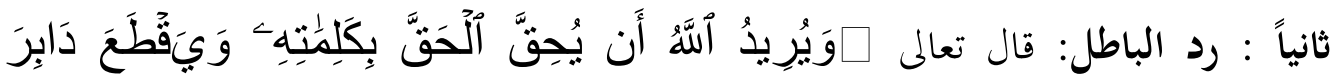

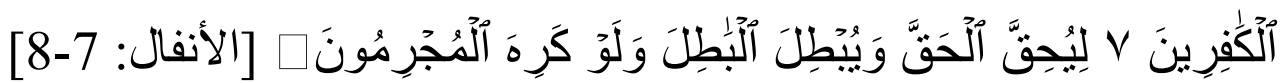

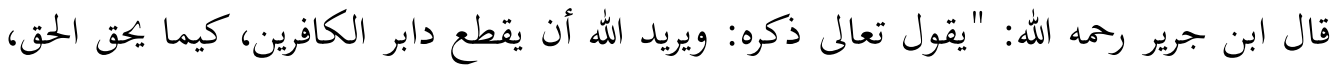
كيما يُعبد الله وحده دون الآلهة والأصنام، ويعزّ الإسلام، وذلك هو "تحقيق الحق"= (ويبطل الباطل)

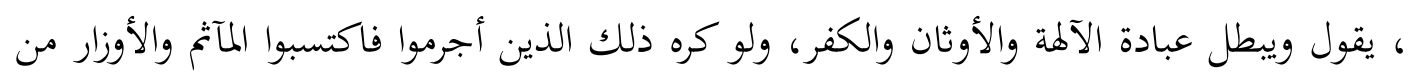

الكفار (Abu Ja'far)" (1)

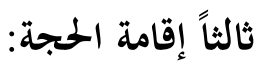

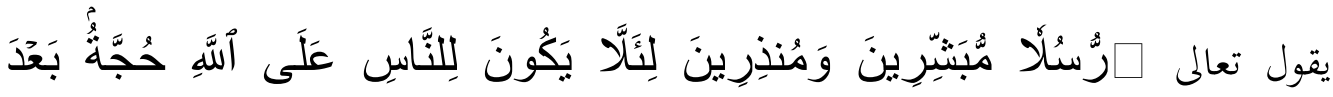

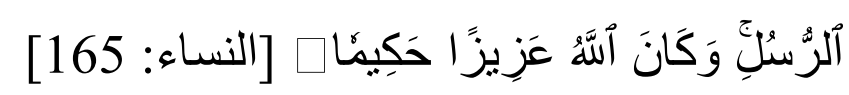
قال الطبري -رحمه الله-: (( فقطع حجة كلّ مبطل ألحسَ في توحيده وخحالف أمره، بجميع معاني الحجج القاطعة عذرَ، إعذارًا منه بذلك إليهم، لتكون لله الحجة البالغة عليهم وعلى جميع خلقه)) .(Abu Ja'far)

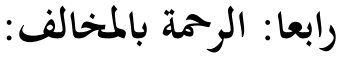

$$
\text { فإن في الرد على المخالف عونا له على أمور عدة، منها: }
$$

أولا: الرجوع إلى الحق بما يتم فيه البيان لخطئه، وإيضاح بعده عن الحق، وضلالته في الأمر المعيّن، فإن كان رجاعا إلى الحق حريصا على سبل الهداية كان في الرد له عونا له على الرجوع ليَّل

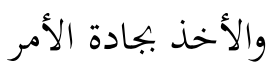




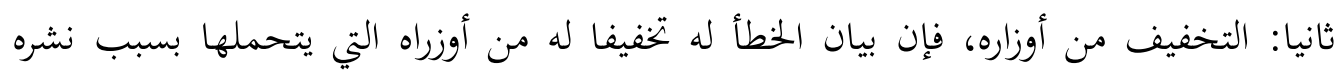
للباطل، أو دفاعه عن الضلالات، فمن ردّ عليه له فهو نعمة ساقها الله له، لينتفع بذلك، ويخف عنه

ثالثا: هداية للأتباع الذي اتبعوا صاحب الباطل دون روية ولا هدى ولا كتاب منير، بل بمجرد التقليد أو العاطفة أو انجرارا خلف الشبهة التي لبّس بها عليهم.

المبحث الثالث : ضوابط الرد على المخالف :

الكلام عن الضوابط في هذا الباب، كلام في غاية الأهمية، حتى لا يترك فيه الحبل على الغارب، ولا ينطلق فيه الناس دون بصيرة، ولا سيما وأن الأمر يتعلق بأعراض الناس بل والعلماء أحيانا، ولذلك ممكن أن نستخلص من تقريرات العلماء الضوابط التالية:

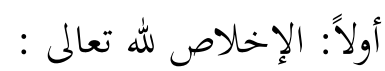

لا يصح عمل يقصد به صاحبه التقرب إلى مولاه إلا أن يكون خالصا له سبحانه وتعالى، فهذا دليل على صحة المسلك وسلامة السبيل، والرد على المخالف إن كانت النية فيه خالصة لله تعالى آتى ثماره اليانعة، أما إن كان لحض النفوس، والانتصار للأهواء المخالفة فلن يبارك لصاحبه فيه، ولا يؤجر عليه، بل يكون مستحقا للإثم في نيته تلك وإن ادعى غير ذلك ظاهرا. وفي الحديث قال عليه الصلاة والسلام: ( إنما الأعمال بالنيات, وإنما لكل امرئ ما نوى, فمن كانت هجرته إلى دنيا Al-Bukhari, no:1; Muslim, ) يصيبها أو إلى امرأة ينكحها, فهجرته إلى ما جاهر إليه .(no:1907 ثانياً: المتابعة للشارع : (not) هدي النبي صلى الله عليه وسلم هو أكمل الهدي وسبيله أقوم السبيل، ولا يخالف عاقل يرجو

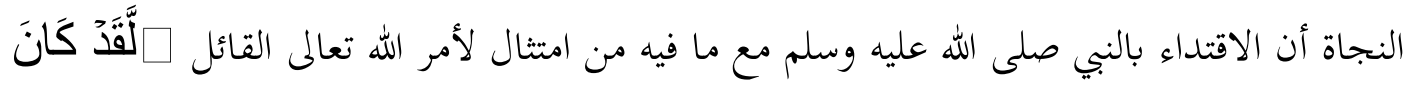

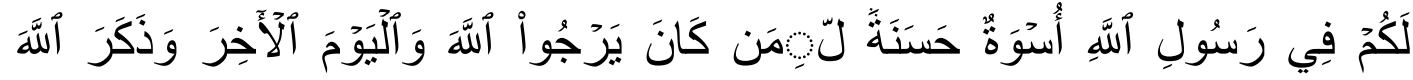


37

محمد بن غالب حسان

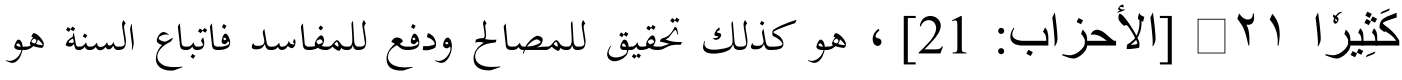
المصلحة المحققة ودفع المفسدة المقصود دفعها، وهذا يحتاج من الدعاة خاصة أن يدرسوا هدي النبي صلى الله عليه وسلم في رده على المخالف سواء كان من أهل الأديان الأخرى أو من أصحابه أو من غيرهم، فيدرس الداعي الهدي النبوي دراسة وافية بمعرفة الأساليب والوسائل والأولويات وفقه الرد الوارد في السنة النبوية، حتى يحقق في رده المصلحة المرجوة من انتفاع المردود عليه ، والنصح لغيره.

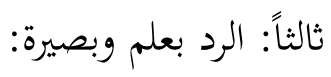

فإن ما يناقض العلم هو الجهل ، والجهل مانع من تحقيق الصواب، بل ومخظور في الشريعة، ولذلك سوءا في هذا الباب أو غيره لا يقبل الكام بجهل يصوّر الأمور على غير حقائقها الصحيحة، ولذلك قال شيخ الإسلام رحمه الله: \ لا بد أن يكون مع الإنسان أصول كلية ترد إليها الجزئيات؛ ليتكلم بعلم وعدل، ثم يعرف الجزئيات كيف وقعت؟ وإلا فيبقى في كذب وجهل في الجزئيات،

وجهل وظلم في الكليات، فيتولد فساد عظيمه (Ibn Taymiyyah(d), 1416h). وقال رحمه الله: "كذلك بيان من غلط في رأي رآه في أمر الدين من المسائل العلمية والعملية فهذا إذا تكلم فيه الإنسان، بعلم وعدل وقصد النصيحة فالله تعالى يثيبه على ذلك لا سيما إذا كان المتكلم فيه داعيًا إلى بدعة فهذا يجب بيان أمره للناس فإن دفع شره عنهم أعظم من دفع شر قاطع الطريق" رابعاً: فهم رأي المخالف ومأخذه: والوقوف على دليله, ومعرفة وجه استدلاله به, وتحديد محل الحلاف, فلا بد من تحديد نقطة الحلاف, فيضبط الراد مضمون رده, ويختاره بعناية . خامساً: أن يكون المقصود نصرة الحق لا مجرد الرد على المخالف: وهذا أمر يعود إلى صحة نية الرادّ وسلامة مقصده، وفي ذلك يقول العلامة السِّجزيُ " وَلِيَكُنْ قَصد

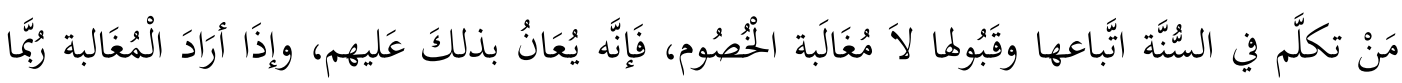
غُلِبَ (Ubaydullah)". 


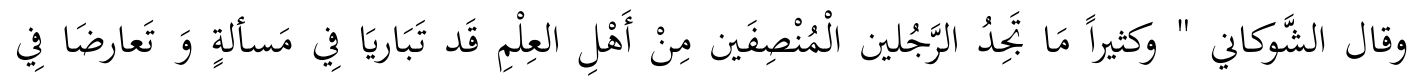

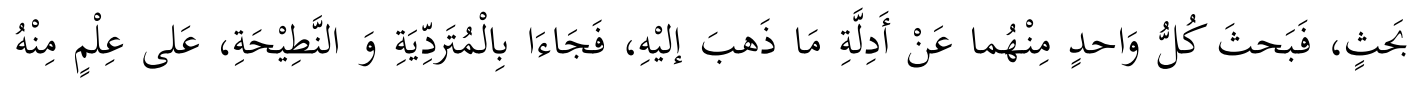

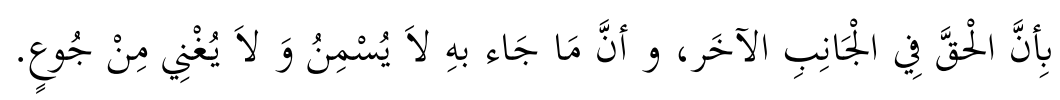

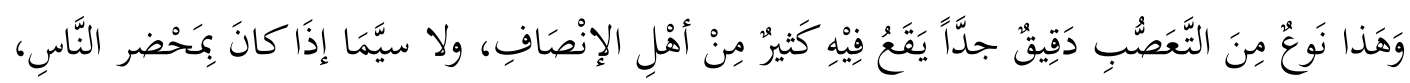

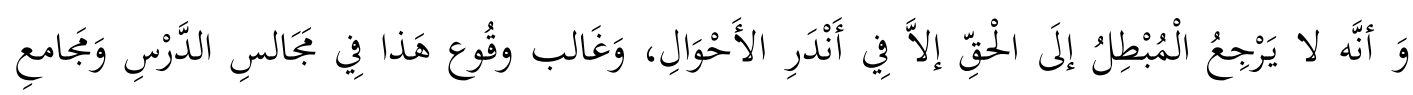
أهْلِ العِلْمِ (Alshawkani)".

سادسا: أن لا يكون رد الخطأ بخطأ: فإن المقصود هو نصرة الحق وليس مجرد الرد، وفي ذلك

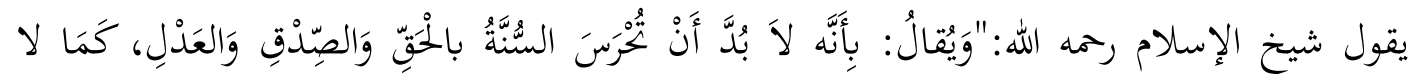

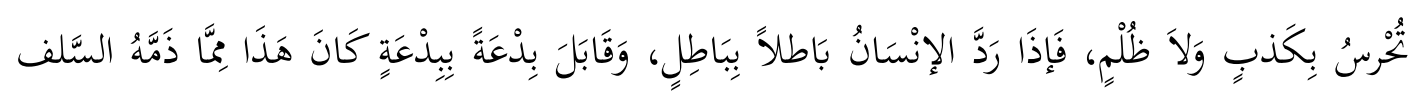
وَالأئمَّة (Ibn Taymiyyah(c) سابعاً: بذل الجهد في هداية المخطئ: إذ الرد على المخطئ كما أن به حرصا على المسلمين أن لا يقعوا في خطئه فكذلك الحرص على المخطئ نفسه أن يؤوب ويرجع إلى الجادة وهو داخل في قوله صلى الله عليه وسلم لعلي ح: ( فو الله لأن يهدي الله بك رجلاً واحداً خير

لك من حمر النعم) (Al-Bukhari, no:3702; Muslim, no:2406).

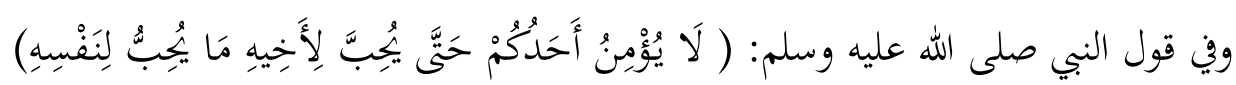
.(Al-Bukhari,no:13; Muslim,no:45) ثامناً: الالتزام بالخلق الحسن في الرد دون السب والسفه: الالتزام بالحلق الحسن هو صفة المؤمن في كل حال، ومن ذلك الرد على المخالف، ولا يعني بذلك بحال من الأحوال من الشدة في الرد

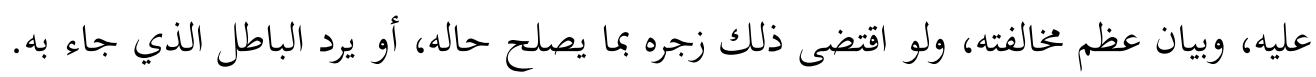
وعلى هذا يحمل ما ورد في تراجم العلماء من شدقم على أهل البدع، ومن ذلك ما ذكره الذهبي في ترجمة الإمام عثمان بن سعيد الدارمي رحمه الله قال عنه:"كان لهجاً بالسنة-واظهر السنة ببلده ودعا غليها وذب عن حريكها وقمع مخالفها - ،بصيراً بالمناظرة، جذعاً في أعين المبتدعة 
39

تاسعا: أن يكون الرد محققا لرد الضلالة لا مجرد رد لا تقوم به حجة:

فإن الرد وإن كان بعلم، لكنه لم يكون نافعا وقويا يبين به الحق ويرد به الباطل فلا انتفاع به، ولا تقوم

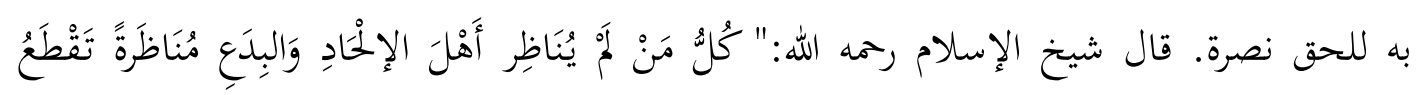

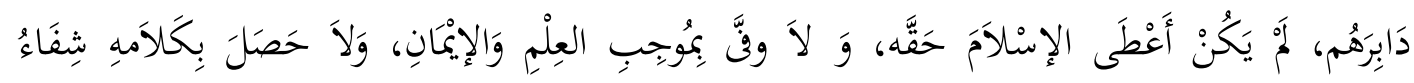

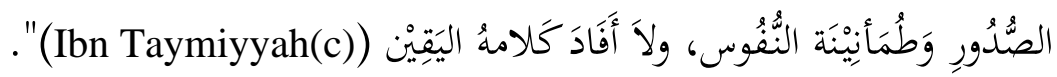
عاشراً: الإنصاف والعدل مع المخالف: إن من القيم الخلقية المطلقة القيام بالعدل مع الخلق جميعاً, بل إن الله سبحانه وتعالى حرَّم الظلم على نفسه, ونزَّه ذاته العلية عن ذلك قال ابن القيم -رحمه الله-: (( فأمرَ سبحانه بالقيام بالقسطِ, وهو العدلُ, وهذا أمرٌ بالقيامِ به في حقِّ كل أحد عدُوًَا كان أو وليّاً, وأحقُّ ما قام له العبد بالقسط: الأقوالُ والأراءُ والمذاهبُ إذْ هي متعلقة بأمرِ الله وخبرِ؛ فالقيام فيها بالهوى والعصبيةِ مضادٌّ لأمر الله, مُنافٍ لما بعثَ به رُسََُه )( 
نستخلص في فاية هذه الدراسة إلى النتائج التالية:

$$
\text { أولا: أن الخلاف أمر كوين واقع في هذه الأمة }
$$

ثانيا: أن الخلاف ينقسم إلى خلاف سائغ وخلاف غير سائغ

ثالثا: أن لكل نوع من نوعي الخلاف أسباب ومظاهره

رابعا: أن الرد على المخالف له الأهمية البالغة في شريعة الإسلام

خامسا: وردت الأدلة الكثيرة من الكتاب والسنة وآثار الصحابة رضي الله عنهم في أمر الرد على

المخالف

سادسا: أن هناك مقاصدا جليلة في الرد على المخالف

سابعا: أن المخالف ليس على درجة واحدة في المخالفة

ثامنا: أن أبرز ما يكون الخلاف المؤثر هو في أمور الاعتقاد، وقد يكون في غيرها وهو أقل تأثيرا.

تاسعا: معرفة الضوابط الشرعية في الرد على المخالف

عاشرا: تقريرات أهل العلم في مسألة الرد، وتنوع عباراهم في ذلك دليل على أهميته.

\section{References:}

Abu Albarakat Abdullah Bin Ahmad Annisfi (Almutawaffaa: 710h), Tafsir Annisfii (Madarik Altanzil Wahaqaaeiq Altaa'wil), Haqqaqah Wakharraja Ahaadithahu: Yusof Ali Badawi, Raaja'ahu Waqaddam Lahu:

Muhyiddiyn Dib Mastu, Alnashir: Dar Alkalim Altayyib, Bayrut

Abu Bakr Al'khilal, Al'aqidah Riwayat Abi Bakr Alkhilal, Almuhaqqiq: Abdulaziz Eizzuddiyn Alsirwan, Alnashir: Dar Qatibah - Dimashq, Attab'ah: Al'uwlaa. 
Abu Dawud Sulayman Bin Al'ash'ath Al'azdi (202 - 275 H) Sunan Abi Dawud, Almuhaqqiq: Shuayb Al'arnaoot, Alnashir: Dar Alrisalat Al'aalamiah, Attab'ah: Al'uwlaa.

Abu Ja'far, Muhammad Bin Jarir Attabari (310h), Jaamie Albayaan Fi Ta'wil Alqur'aani, Tawzie: Dar Attarbiyyat Watturaath - Makkah Almukarramah.

Ahmad Bin Hanbal Abu Abdullah(a) (Almutawaffa: 241h), Alradd Ala Aljahmiah, Almuhaqqiq: Sabri Bin Salaamat Shahin, Alnashir: Dar Althabat Lilnashr Wattawzie.

Ahmad Bin Hanbal Abu Abdullah(b) (164 - 241h) Musnad Ahmad, Almuhaqqiq: Shuayb Al'arnaoot - Aadil Murshid, Wa Aakharun, Ishraf: Dr. Abdullah Bin Abdulmuhsin Alturky, Alnashir: Muassasat Alrisalat.

Al'Albani Muhammad Naasiruddin, (Almutawaffaa: 1420h), Alsilsilah Assahihah, Alnashir: Maktabat Almaarif Lilnashr Waltawziei, Alriyad, Attab'ah: Al'uwlaa.

Al'Albani Muhammad Naasiruddin, (Almutawaffaa: 1420h), Silsilah Al'Ahaadith Aldaeifah, Dar Alnashr: Dar Almaarif, Alriyad - Almamlakah Al'arabiah Alsaeudiah, Attab'ah: Al'uwlaa.

Al-Bukhari (1422h), Abu Abdullah Muhammad Bin Ismaeil Al-Bukhari, Sahih Al-Bukhari, Einayatuh: Dr. Muhammad Zahir Annaasir, Attab'ah: Al'uwlaa Aam 1422h. Dar Towq Alnajaah.

Alqizwaani, Abu Abdullah Muhammad Bin Yazid Alqizwani, (Almutawaffaa: 273ha), Sunan Ibn Maajah, Tahqiq: Muhammad Fuad Abd Albaqi, Alnashir: Dar Ihya Alkutub Al'arabiah.

Alqurtubii Abu Muhammad Ali Bin Ahmad Bin Saeid Bin Hazm Al'andalusi Alqurtubii Alzzahirii (Almutawaffaa: 456h), Al'ihkam Fi 'Usul Al'ahkaam, Almuhaqqiq: Alshaykh 'Ahmad Muhammad Shakir, Qaddama Lahu: Al'ustadh Alduktur 'Iihsan Abbas, Alnashir: Dar Alaafaq Aljadidah, Bayrut

Alraazi (1399h), Ahmad Bin Faris Bin Zakaria Alqazwayni Alraazi, Abu Alhusayn (Almutawaffaa: 395h) Mu'jam Maqaayis Allughah, Almuhaqqiq: Abdussalam Muhammad Harun, Alnashir: Dar Alfikr, Aam Alnashr: $1399 \mathrm{~h}$ 
Alsa'di, Abdulrahman Bin Nasir Bin Abdullah Alsa'di (Almutawaffa: 1376h), Tafsir Alkarim Alrahmaan Fi Tafsir Kalaam Almannaan, Almuhaqqiq: Abdulrahman Bin Ma'ala Alluwayhiq, Alnashir: Muassasat Alrisalah, Attab'ah: Al'uwlaa.

Alshaatibi, Ibrahim Bin Musa Bin Muhammad Alshaatibi (Almutawaffaa: 790h), Al-Ietisam, Tahqiq: Salim Bin Eyd Alhilali, Alnashir: Dar Ibn Affaan, Suodiyyah, Attab'ah: Al'uwlaa.

Alshawkani, Muhammad Bin Ali Bin Muhammad Bin Abdillah Alshawkani (Almutawaffaa: 1250h) Adab Attalab, Almuhaqqiq: Abdullah Yahyaa Assarihi, Alnashir: Dar Ibn Hizm - Lubnan / Bayrut, Attab'ah: Al'uwlaa.

Alshaybany Ibn Abi Aasim, Abu Bakr Alshaybany (Almutawaffaa: 287h), Alsunnah, Almuhaqqiq: Muhammad Nasir Naasiruddin Al'Albani, Alnashir: Almaktab Al'Islaami - Bayrut, Attab'ah: Al'uwlaa.

Al Uthaymin Muhammad Bin Salih Al Uthaymin (Almutawaffaa: 1421h) Sharh Al'aqidah Assafaariniyah, Alnashir: Dar Alwatan Lilnashri, Alriyadh, Attab'ah: Al'uwlaa.

Annawawi (1392h), Abu Zakaria Muhyuddiyn Alnawawii (Almutawaffaa: 676h), Alminhaaj Sharh Sahih Muslim Bin Alhajjaj, Alnashir: Dar Ihya Alturaath Al'arabi - Bayrut, Attab'ah: Althaaniah, 1392h.

Attirmidhi Muhammad Bin Eisaa Attirmidhi (Almutawaffa: 279h), Sunan Attirmidhi, Tahqiq Wata'liq: Ahmad Muhammad Shakir, Alnashir: Sharikat Maktabat Wamatba'at Mustafaa Albabi Alhalabii

Ibn Alqayyim Muhammad Bin Abi Bakr(a) (Almutawaffa: 751h), Zad Alma'aad Fi Hadyi Khayr Al-Ebaad, Alnashir: Muassasat Alrisalat, Bayrut

Ibn Alqayyim Muhammad Bin Abi Bakr(b) (Almutawaffaa: 751h), Madarij Alsaalikin Bayn Manazil Iyyaaka Na'budu Wa'iyyaaak Nasta'ein, Almuhaqqiq: Muhammad Almu'tasim Billah Albaghdadi, Alnashir: Dar Alkitab Al'arabi - Bayrut, Attab'ah: Althaalithah.

Ibn Alqayyim Muhammad Bin Abi Bakr(c) (Almutawaffaa: 751h), Zad Almuhaajir Ilaa Rabbih, Alrisalat Attabukiyah, Almuhaqqiq: Dr. Muhammad Jamil Ghazi. 
Ibn Battah Abu Abdillah Ubaydallah Bin Muhammad Bin Muhammad Bin Hamdan Al-Ukbary Almaeruf Bi Ibn Battah Al-Ukbary (Almutawaffaa: 387h), Al-Ibanah Alkubraa, Al-Muhaqqiq: Rida Mu'ti, Wa Uthman AlEthyubii, Wa Yusof Alwabil, Wa Al-Walid Bin Sayfannasr, Wa Hamd Altuwyjri, Alnashir: Dar Ar-Raayah Linnashr Wattawzie, Arriyadh

Ibn Hibbaan, Altamimi, Abu Hatim, Aldaarimi, Albusti (Almutawaffaa: 354h), Kitab Almajruhin, Almuhaqqiq: Mahmud Ibrahim Zaayid, Alnashir: Dar Alwa'ey - Halab.

Ibn Manzur, Muhammad Bin Mukrim Bin Ali, (Almutawaffa: 711h), Lisaan Al'Arab, Alnashir: Dar Saadir - Bayrut

Ibn Rajab Alhanbaly, (Almutawaffaa: 795h), Alfarq Bayna Alnasihah Waltaghyir, Allaq alayhi Wakharraja Ahaadithah: Ali Hasan Ali Abdulhamid, Alnashir: Dar Ammar, Oman

Ibn Taymiyyah(a), Taqi Addiyn Abu Al-abbas Ahmad Bin Abdulhalim Ibn Taymiyyah, (Almutawaffaa: 728h), Iqtidaa Alsirat Almustaqim, Almuhaqqiq: Nasir Abdulkarim Al-Aql, Alnashir: Dar Aalim Alkutub, Bayrut, Lubnan

Ibn Taymiyyah(b), Taqi Addiyn Abu Al-abbas Ahmad Bin Abdulhalim Ibn Taymiyyah Alharaani (Almutawaffaa: 728h), Alradd Ala Albikri, Diraasat Watahqiq: Dr. Abdullah Bin Dajin Alsahly, Alnashir: Maktabat Dar Alminhaj Lilnashr Wattawzie.

Ibn Taymiyyah(c), Taqi Addiyn Abu Al-abbas Ahmad Bin Abdulhalim Ibn Taymiyyah Alharaani (Almutawaffaa: 728h), Dar Taearud Aleaql Walnaql, Tahqiq: Alduktur Muhammad Rashad Salim, Alnashir: Jamieat Al'Imam Muhammad Bin Sueud Al'Islamiah,

Ibn Taymiyyah(d), Taqi Addiyn Abu Al-abbas Ahmad Bin Abdulhalim Ibn Taymiyyah Alharaani (1416h), (Almutawaffaa: 728h), Majmuw Alfataawaa, Almuhaqqiq: Abdulrahman Bin Muhammad Bin Qasim, Alnashir: Majma' Almalik Fahad Litiba'at Almushaf Alsharif, Almadinah Alnabawiyyah, Almamlakah Al'arabiah Alsaeudiah, Aam Alnashr: 1416h

Ibn Uthaymin, (Almutawaffaa: 1421h), Alkhilaaf Bayna Al-Ulama, Alnashir: Dar Alwatan Linnashr, Attab'ah: 1423h. 


$$
\text { الرد على المخالف الأهمية والضوابط }
$$

Muslim, Abu Alhusayn Muslim Bin Alhajjaj Alqashiri (206 - 261h), Sahih Muslim, Almuhaqqiq: Muhammad Fuad Abd Albaqy, Alnashir: Dar Ihya Alkutub Al'arabiah

Shamsuddin Addhahabii (Almutawaffaa: 748h), Siyar A 'lam Annubala, Almuhaqqiq : Majmuat Min Almuhaqqiqin Bi'Iishraf Alshaykh Shuayb Al'arnaoot, Alnashir : Muassasat Alrisaalati, Attab'ah : Atthaalitha.

Sulayman Bin Ahmad (Almutawaffaa: 360h), Mu'jam Altabaraani, Tahqiq: Fariq Min Albaahithin Bi Iishraf Wa'einayat Dr. Sa'd Bin Abdullah Alhamid wa Dr Khalid Bin Abdulrahman Aljarisi.

Ubaydullah Bin Saeid Alsajzy (Almutawaffaa: 444h) Alradd Ala Man Ankar Alharf Wassawt, Almuhaqqiq: Muhammad Ba Karim Ba Abdullah, Alnashir: Emaadat Albahth Al-Ilmi Bi Aljamieat Al'Islamiah. 